Atmos. Chem. Phys., 13, 10397-10404, 2013

www.atmos-chem-phys.net/13/10397/2013/

doi:10.5194/acp-13-10397-2013

(c) Author(s) 2013. CC Attribution 3.0 License.
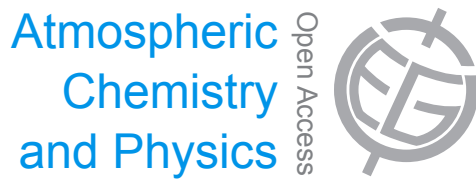

\title{
Proton affinities of candidates for positively charged ambient ions in boreal forests
}

\author{
K. Ruusuvuori ${ }^{1}$, T. Kurtén ${ }^{2}$, I. K. Ortega ${ }^{1}$, J. Faust ${ }^{1,3}$, and H. Vehkamäki ${ }^{1}$ \\ ${ }^{1}$ Division of Atmospheric Sciences, Department of Physics, P.O. Box 64, 00014 University of Helsinki, Finland \\ ${ }^{2}$ Laboratory of Physical Chemistry, Department of Chemistry, P.O. BOX 55, 00014 University of Helsinki, Finland \\ ${ }^{3}$ Department of Chemistry, University of Wisconsin-Madison, 1101 University Avenue, Madison, Wisconsin 53706-1322, \\ USA
}

Correspondence to: K. Ruusuvuori (kai.ruusuvuori@helsinki.fi)

Received: 10 January 2013 - Published in Atmos. Chem. Phys. Discuss.: 22 April 2013

Revised: 16 August 2013 - Accepted: 6 September 2013 - Published: 28 October 2013

\begin{abstract}
The optimized structures and proton affinities of a total of 81 nitrogen-containing bases, chosen based on field measurements of ambient positive ions, were studied using the CBS-QB3 quantum chemical method. The results were compared to values given in the National Institute of Standards and Technology (NIST) Chemistry WebBook in cases where a value was listed. The computed values show good agreement with the values listed in NIST. Grouping the molecules based on their molecular formula, the largest calculated proton affinities for each group were also compared with experimentally observed ambient cation concentrations in a boreal forest. This comparison allows us to draw qualitative conclusions about the relative ambient concentrations of different nitrogen-containing organic base molecules.
\end{abstract}

\section{Introduction}

Electric charge plays a central role in atmospheric sciences. For example, sample ionization is employed in many measurement devices such as the chemical ionization mass spectrometer (CIMS) (Eisele and Tanner, 1991). This is because ionizing the sample makes it possible to detect particles of smaller sizes than what could have been measured had the sample remained neutral. However, in order to relate such measurement results to actual atmospheric conditions, we need to understand the possible effects of the ionization process on the molecules or clusters being charged as well as on the chemistry of the ionized sample. Furthermore, since the atmosphere does not consist only of neutral molecules and clusters, the identification of ambient ions and ionization processes under different atmospheric conditions is essential in understanding the role of ions in atmospheric chemistry or in particle formation. Knowing which molecules will most likely carry a charge will aid the development of a comprehensive picture of these atmospheric processes. An easy way of assessing this question is to examine the proton affinities of molecules.

The proton affinity (PA) is an important thermodynamic quantity. It relates to the enthalpy of the molecule and is a measure of its gas-phase basicity, which in turn relates to the Gibbs free energy. This relation can be seen from the formula for Gibbs free energy:

$G=H-T S$,

where $H$ is the enthalpy, $T$ the temperature and $S$ the entropy. In atmospheric ion-neutral collisions, molecules with the highest PA (bases) will end up collecting the positive charges, and the ones with the lowest PA (acids) will end up with negative charges. Unfortunately, absolute gas-phase PAs are hard to measure. Instead, measurements usually yield relative values. To convert these relative values into absolute PAs reliably, theoretical methods need to be used to anchor the PA scale. Theoretical methods can also be used to help interpret experimental data by directly calculating the desired PAs. However, theoretical results often depend on the method used, and the performance of the methods may vary with the type of molecule being studied. For this reason, theoretical calculations need to be combined with both benchmark calculations, and comparisons with experiments. 

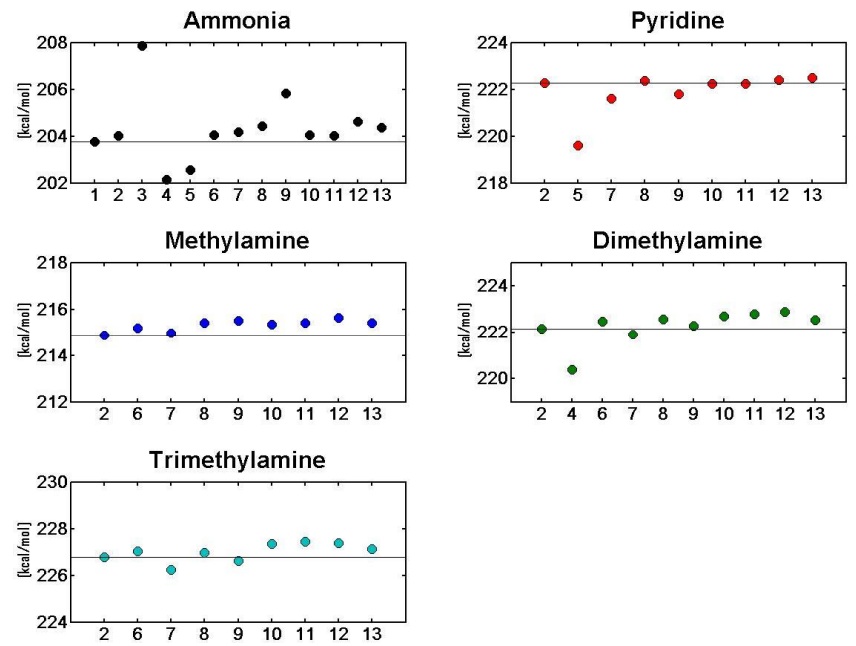

Fig. 1. Benchmark results. Values on the $y$ axis are in $\mathrm{kcal} \mathrm{mol}^{-1}$. Values on the $x$ axis are labels corresponding to the numbers assigned to different sources and methods in Table 1. Horizontal lines mark the PA value given in NIST, except in the case of ammonia, where it marks the PA value calculated by Czakó et al. (2008).

Our aim was to study the absolute values of PAs of atmospherically relevant bases using quantum chemical methods. These methods were applied to several molecular ion species, which were selected based on the experimental measurements of ambient ions in boreal forests by Ehn et al. (2010). Although the National Institute of Standards and Technology (NIST) WebBook contains data of over 40000 compounds, several PAs with possible atmospheric relevance are missing. The values that are listed for the cases under study are all evaluated values taken from a single review article (Hunter and Lias, 1998). Thus, the absolute values are useful by themselves, but we also wanted to see whether there was any correlation between the PAs and the observed mass spectrum peaks for the cations, which could help in interpreting the experimental results.

\section{Methods and computational details}

The experimental measurements of ambient ions in boreal forests by Ehn et al. (2010) included both positively and negatively charged ions. The molecules that were subjected to study were selected based on the molecular formula of the (uncharged) compounds identified in the measured positive mass spectra. For all 16 different molecular formulae (minus the proton), we first looked at cases that had a PA given in NIST and selected the isomers with the largest and the smallest PA along with a few others for comparison. For the three cases with the highest observed mean of $30 \mathrm{~min}$ ion concentration averages - labeled as pyridine, alkyl pyridine (1) and alkyl pyridine (2) in Figs. 1 and 2 in this work - we calculated the PA of all isomers listed in NIST (except ones with

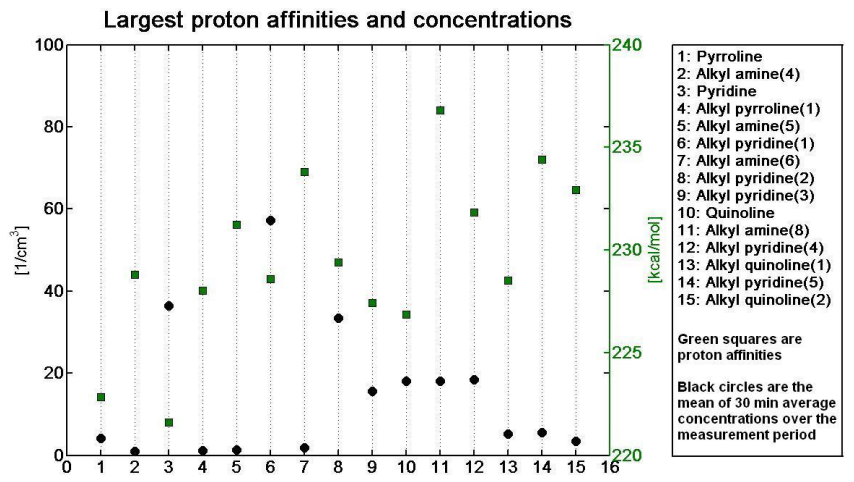

Fig. 2. Largest calculated proton affinities (green squares) for each compound and the mean of $30 \mathrm{~min}$ average concentrations over the measurement period (black circles; Ehn et al., 2010). The value of the $x$ axis is merely an index referring to the legend.

additional molecular species such as deuterium or chloride) regardless of whether NIST gave a PA value for them or not.

Initial guesses of molecular geometries for all calculations were constructed by hand using ADF-GUI (ADF-GUI, 2009), the graphical user interface of the computational chemistry program ADF. Some of the geometries were also optimized using the universal force field (UFF) (Rappe et al., 1992) method, which was the default in ADF-GUI, before running higher level calculations. However, in some cases this led to unrealistic configurations. In such cases this initial optimization step was simply skipped.

Benchmarking calculations of the structures and proton affinities were performed using the quantum chemical methods W1BD (Martin and de Oliveira, 1999; Barnes et al., 2009), G2 (Curtiss et al., 1991), G3 (Curtiss et al., 1998), G4 (Curtiss et al., 2007), CBS-QB3 (Montgomery Jr. et al., 1999, 2000), CBS-APNO (Ochterski et al, 1996) and CBS4M (Ochterski et al., 1996; Montgomery Jr. et al., 2000) implemented in Gaussian 09 (Frisch et al., 2009). The G2 calculations also provided G2MP2 (Curtiss et al., 1993) energies. Each method is a model chemistry method consisting of several computational steps, developed to provide accurate thermochemical values. The W1BD method is a variation of Weizmann-1 theory, where Brueckner doubles are used, and while strictly speaking it is not an ab initio method, its "empirical" parameter is actually derived from W2 calculations and not actual experiments. The Gaussian- $n$ methods (G2, G3, etc.) are close to the complete basis set (CBS) methods: the Gaussian- $n$ methods use high accuracy methods with medium-sized basis sets and then correct for errors using some empirical parameters, whereas the CBS methods start similarly but employ an extrapolation to reach the basis set limit and use empirical parameters to correct for systematic errors. The actual performance of the different methods may vary from case to case due to, for example, fortuitous error cancellation. From a purely theoretical standpoint, the W1BD method is the most accurate and computationally 
demanding of these methods, while the CBS-4M method is considerably faster than the other methods, but it sacrifices some accuracy to achieve this. The G2, G3, G4, CBS-QB3 and CBS-APNO methods are generally of roughly comparable accuracy, but speed varies with CBS-QB3 proving to be the fastest method in our calculations and G4 being the slowest.

In addition to these methods, three other methods were included in the comparison. The results of the multi-step approach B3LYP/CBSB7//RI-CC2/aug-cc-pV $(T+d) Z$ have been previously published and described in detail by $\mathrm{Ku}-$ piainen et al. (2012). The B3LYP/CBSB7 proton affinity for ammonia was calculated from the unpublished data for the first step of these calculations. The B3LYP/6$31++\mathrm{G}(2 \mathrm{df}, 2 \mathrm{dp}) / / \mathrm{RI}-\mathrm{MP} 2-\mathrm{F} 12 / \mathrm{cc}-\mathrm{pVDZ}-\mathrm{F} 12$ method comprised of geometries and thermodynamic corrections calculated with Gaussian 09 at the B3LYP/6-31++G(2df,2dp) level and electronic energies calculated with Turbomole 6.3 (Ahlrichs et al., 1989, Turbomole 6.3, Turbomole GmbH) at the RI-MP2-F12/cc-pVDZ-F12 level. A more detailed description of the method as well as all the relevant references can be found in Ryding et al. (2012).

After the benchmarking, a quantum chemical study of the structure and proton affinities of several compounds with the molecular formulae $\mathrm{C}_{4} \mathrm{H}_{7} \mathrm{~N}, \mathrm{C}_{4} \mathrm{H}_{11} \mathrm{~N}, \mathrm{C}_{5} \mathrm{H}_{5} \mathrm{~N}, \mathrm{C}_{5} \mathrm{H}_{9} \mathrm{~N}$, $\mathrm{C}_{5} \mathrm{H}_{13} \mathrm{~N}, \mathrm{C}_{7} \mathrm{H}_{6}, \mathrm{C}_{6} \mathrm{H}_{7} \mathrm{~N}, \mathrm{C}_{6} \mathrm{H}_{15} \mathrm{~N}, \mathrm{C}_{7} \mathrm{H}_{9} \mathrm{~N}, \mathrm{C}_{8} \mathrm{H}_{11} \mathrm{~N}, \mathrm{C}_{9} \mathrm{H}_{7} \mathrm{~N}$, $\mathrm{C}_{8} \mathrm{H}_{19} \mathrm{~N}, \mathrm{C}_{9} \mathrm{H}_{13} \mathrm{~N}, \mathrm{C}_{10} \mathrm{H}_{9} \mathrm{~N}, \mathrm{C}_{10} \mathrm{H}_{15} \mathrm{~N}$ and $\mathrm{C}_{11} \mathrm{H}_{11} \mathrm{~N}$ was performed using CBS-QB3. All cases under study needed to be simulated both with a neutral and a positive charge in order to determine their proton affinities. The CBS-QB3 method starts with a geometry optimization with the B3LYP (Lee et al., 1988; Becke, 1993) density functional and a 6$311 \mathrm{G}(2 \mathrm{~d}, \mathrm{~d}, \mathrm{p})$ basis set, followed by a frequency calculation using a scaling factor of 0.99 . The final CBS energies are then extrapolated based on single-point calculations at the CCSD(T) (Raghavachari et al., 1989), MP4SDQ (Trucks et al., 1988) and MP2 (Møller and Plesset, 1934; Head-Gordon et al., 1988) levels.

In all cases, proton affinities were calculated as the standard enthalpy (i.e., at $298.15 \mathrm{~K}$ and $1 \mathrm{~atm}$ reference pressure) change of the reaction $X+H^{+} \rightarrow X H^{+}$. The enthalpy of the proton was taken to be exactly $2.5 \mathrm{RT}$, where $\mathrm{R}$ is the gas constant. Gas-phase basicities were calculated from the Gibbs free energy change of the protonation reaction. The Gibbs free energy for the proton was calculated with CBSQB3 to be -0.01 hartree. Including the benchmarking calculations, a total of 81 proton affinities and gas-phase basicities were calculated in this study. The optimized geometries as well as the calculated values for the zero-point-corrected electronic energy, the standard enthalpy and the Gibbs free energy for both neutral and protonated cases of the studied molecule species are presented in the Supplement.

\section{Results and discussion}

The benchmarking results are shown in Fig. 1 and Table 1. Due to limitations in computational resources, we were unable to obtain a result for the PA of pyridine with the W1BD method. In the cases of methylamine, dimethylamine and trimethylamine, we compared all other methods with the W1BD. In the case of pyridine, all results were compared to the PA value listed in NIST. In the case of ammonia, all results were compared with the PA determined by Czakó et al. (2008). This PA is the result of very high-level quantum chemical calculations. Due to the structural simplicity of the ammonia molecule, quantum chemical calculations can be expected to lead to quantitatively reliable values for this molecule, which means that ammonia is a good molecule for anchoring the PA scale.

Based on the benchmarking results, all of the CBS and $\mathrm{G}$ methods performed well, with most numerical results deviating from the reference values by less than $1 \mathrm{kcal} \mathrm{mol}^{-1}$. The only clear exception is the CBS-4M result for the PA of ammonia, which is roughly $2 \mathrm{kcal} \mathrm{mol}^{-1}$ greater than the value obtained by Czakó et al. (2008). Although the differences in the other benchmarking calculations were so small that the all of the CBS and G methods could be considered of equal accuracy, the ammonia result showed that the CBS4M method was less reliable than the rest of the CBS or G methods. For the cases studied in the benchmarking phase, the speed advantage of the CBS-4M method was not considered significant, as the second fastest method, the CBS-QB3, finished the same calculations in around ten minutes or less. Also, the results for mono-, di- and trimethylamine suggest that the CBS-QB3 method will very slightly underestimate the PA, thus providing a lower bound. Furthermore, as this same method was used to calculate some PAs and gas-phase acidities as well as formation enthalpies and free energies in the paper by Ehn et al. (2010), our results should provide an interesting comparison. Therefore, we chose to use CBSQB3 for the remainder of this study.

The CBS-QB3 proton affinity results are listed in Table 2. Including the benchmark calculations, a total of 52 of the molecules had a PA listed in NIST. As stated in the introduction, the values listed in NIST were all from a proton affinity review article by Hunter and Lias (1998), who evaluated absolute values for PAs. The exact details of this evaluation can be found in the original article, but the basic idea was to use computational PAs as well as experimental data in determining a suitable PA scale and then adjust experimental and relative PA values based on this scale. Since the computational values used to determine the PA scale play a key role in this kind of an evaluation, it should be noted that the computational values used by Hunter and Lias were calculated with a slightly modified G2 method (Smith and Radom, 1993). Based on our benchmarking calculations, the standard G2 method is comparable in accuracy with the CBS-QB3 method, so the good general agreement with the evaluated 
Table 1. An overview of the benchmark calculations. All values are in kcal/mol.

\begin{tabular}{|c|c|c|c|c|c|c|}
\hline \multirow[b]{2}{*}{ \# } & & \multicolumn{5}{|c|}{ Proton affinity $\left(\mathrm{kcal} \mathrm{mol}^{-1}\right)$} \\
\hline & & Ammonia & Pyridine & Methylamine & Dimethylamine & Trimethylamine \\
\hline 1 & Czakó et al. (2008) & 203.77629 & - & - & - & - \\
\hline 2 & NIST & 204.01500 & 222.27500 & 214.86600 & 222.15600 & 226.79300 \\
\hline 3 & B3LYP/CBSB7 & 207.86000 & - & - & - & - \\
\hline 4 & $\begin{array}{l}\text { B3LYP/CBSB7/RI-CC2/ } \\
\text { aug-cc-pV }(T+d) Z^{*}\end{array}$ & 202.13000 & - & - & 220.38000 & - \\
\hline 5 & $\begin{array}{l}\text { B3LYP/6-31++G(2d } f, 2 \mathrm{~d} p) / \\
\text { RI-MP2-F12/ cc-pVDZ-F12 }\end{array}$ & 202.54049 & 219.60531 & - & - & - \\
\hline 6 & W1BD & 204.06209 & - & 215.20163 & 222.46944 & 227.04712 \\
\hline 7 & CBS-QB3 & 204.18571 & 221.59971 & 214.96255 & 221.90970 & 226.24454 \\
\hline 8 & CBS-APNO & 204.42040 & 222.36590 & 215.41185 & 222.56796 & 226.95488 \\
\hline 9 & CBS-4M & 205.81096 & 221.78106 & 215.50409 & 222.28558 & 226.60535 \\
\hline 10 & $\mathrm{G} 2$ & 204.04013 & 222.23224 & 215.33969 & 222.69597 & 227.34330 \\
\hline 11 & G2MP2 & 204.00813 & 222.23789 & 215.39930 & 222.79135 & 227.43304 \\
\hline 12 & G3 & 204.61932 & 222.40732 & 215.64528 & 222.88046 & 227.36527 \\
\hline 13 & G4 & 204.36330 & 222.50458 & 215.40369 & 222.55353 & 227.14250 \\
\hline
\end{tabular}

${ }^{*}$ Kupiainen et al. (2012).

results and CBS-QB3 results is not surprising. The differences between our results and those taken from the review article are mostly on the order of $1-2 \mathrm{kcal} \mathrm{mol}^{-1}$, but as the G2 method is slightly different compared to the CBS-QB3 method and as the basis of the evaluated values is experimental values, some variation is to be expected.

There is one case where the CBS-QB3 proton affinity differs from the evaluated PA by a larger margin: tropylium, for which the difference between the two values is $\sim 20 \mathrm{kcal} \mathrm{mol}^{-1}$. The reason for this discrepancy is most likely the fact that tropylium cation is not formed in a simple protonation reaction of the precursor neutral molecule, but by a process called the McLafferty rearrangement (McLafferty, 1959). While the calculated PA should be accurate for the simple protonation reaction it was calculated for, it may not be applicable for the actual chemical reaction forming the tropylium ion. The large difference between CBS-QB3 and NIST PAs likely reflects this. Unfortunately, we were unable to find a satisfactory way around the problem. Because of this, tropylium has been omitted from Figure 2, although the value can still be found in Table 2 for the sake of completeness. Due to the general agreement with the NIST values, it is reasonable to assume that the calculated proton affinities, which had no corresponding value listed in NIST, remain reliable.

Figure 2 shows the experimentally observed mean of $30 \mathrm{~min}$ average concentrations in units of $1 \mathrm{~cm}^{-3}$ for each compound type (elemental composition) identified in the experiments of Ehn et al. (2010), with the largest computational proton affinity for the same compound types. It should be noted for clarity that since the measurements were done on ambient ions, and since we have studied only compounds identified from the positive mass spectra, the concentrations are actually for the protonated versions of the listed compounds. As we are comparing the concentrations - of which we would actually need only qualitative results - to proton affinities, this is just a notational detail and does not affect the results. The actual comparison between the data points shown in Fig. 2 shows no clear correlation between the proton affinities and the observed ion concentrations. This is not surprising given that the ion concentration depends not only on the proton affinity but also on the concentration of the neutral parent molecule. However, we can still extract some information from the individual values. A large observed concentration implies two possibilities: either the observed molecular species has a large proton affinity - which would lead to a large fraction of the molecules becoming charged - or the observed molecule species is abundant in the atmosphere - which could lead to a large number of charged molecules even when only a small or moderate fraction of the parent molecules become charged.

The computed gas-phase basicities (GB) or proton affinities can be used to assess the relative abundances of neutral precursor molecules based on the measured ratios of the protonated ions. If the concentration of two molecules $\mathrm{A}$ and $\mathrm{B}$ are large enough that the collision frequency of neutral A and $\mathrm{B}$ with their protonated forms $\mathrm{HA}^{+}$and $\mathrm{HB}^{+}$are significantly larger than the loss rates of these ions (due to recombination with anions or scavenging onto aerosol particles), then the following equilibrium will hold:

$$
\frac{[\mathrm{A}]}{[\mathrm{B}]}=e^{\frac{1}{\mathrm{RT}}[\mathrm{GB}(\mathrm{A})-\mathrm{GB}(\mathrm{B})]} \frac{\left[\mathrm{HA}^{+}\right]}{\left[\mathrm{HB}^{+}\right]} \approx e^{\frac{1}{\mathrm{RT}}[\mathrm{PA}(\mathrm{A})-\mathrm{PA}(\mathrm{B})]} \frac{\left[\mathrm{HA}^{+}\right]}{\left[\mathrm{HB}^{+}\right]},
$$


Table 2. Proton affinities and gas-phase basicities of all studied molecules. Values are in $\mathrm{kcal} \mathrm{mol}^{-1}$.

\begin{tabular}{|c|c|c|c|c|c|}
\hline & \multicolumn{3}{|c|}{$\begin{array}{l}\text { Proton affinity } \\
\left(\mathrm{kcal} \mathrm{mol}^{-1}\right)\end{array}$} & \multirow[t]{2}{*}{$\begin{array}{l}\Delta \mathrm{PA}^{\mathrm{a}} \\
\left(\mathrm{kcal} \mathrm{mol}^{-1}\right)\end{array}$} & \multirow[t]{2}{*}{$\begin{array}{l}\text { Gas-phase basicity } \\
\left(\mathrm{kcal} \mathrm{mol}^{-1}\right)\end{array}$} \\
\hline & CBS-QB3 & NIST & Other & & \\
\hline Ammonia & 204.18571 & 204.01500 & $204.06000^{b}$ & 0.17071 & 196.78870 \\
\hline Methylamine & 214.96255 & 214.86600 & - & 0.09655 & 207.40490 \\
\hline Dimethylamine & 221.90970 & 222.15600 & $222.68200^{c}$ & -0.24630 & 214.39723 \\
\hline Trimethylamine & 226.24454 & 226.79300 & - & -0.54846 & 218.77097 \\
\hline Pyrroline & 222.82649 & - & $221.27200^{\mathrm{d}}$ & - & 215.30524 \\
\hline 3-Pyrroline & 222.82085 & - & $222.51400^{\mathrm{d}}$ & - & 215.31591 \\
\hline \multicolumn{6}{|l|}{ Alkyl amine (4) $\left(\mathrm{C}_{4} \mathrm{H}_{11} \mathrm{~N}\right)$ : } \\
\hline Ethanamine, N-ethyl- & 227.11615 & 227.62900 & - & -0.51285 & 219.61246 \\
\hline 1-Butanamine & 219.98137 & 220.24400 & - & -0.26263 & 212.47078 \\
\hline Ethanamine, $N, N$-dimethyl- & 228.81230 & 229.46900 & - & -0.65670 & 221.37325 \\
\hline 2-Propanamine, $N$-methyl- & 227.56670 & 227.62900 & - & -0.06230 & 219.86849 \\
\hline \multicolumn{6}{|l|}{ Pyridine $\left(\mathrm{C}_{5} \mathrm{H}_{5} \mathrm{~N}\right)$ : } \\
\hline Pyridine & 221.59971 & 222.27500 & $221.89300^{\mathrm{e}}$ & -0.67529 & 213.96739 \\
\hline Bicyclo[1.1.0]butane-1-carbonitrile & 208.73076 & - & - & - & 201.18315 \\
\hline cis-1-cyano-1,3-butadiene & 194.64946 & - & - & - & 187.96154 \\
\hline cyclo-propene-3-carbonitrile, 1-methyl & 197.85854 & - & - & - & 190.73011 \\
\hline 2,4-Pentadienenitrile & 194.65511 & - & - & - & 187.96718 \\
\hline 4-Cyano-1-butyne & 187.32580 & - & - & - & 180.09320 \\
\hline trans-1-cyano-1,3-butadiene & 194.64507 & - & - & - & 187.95401 \\
\hline \multicolumn{6}{|l|}{ Alkyl pyrroline(1) $\left(\mathrm{C}_{5} \mathrm{H}_{9} \mathrm{~N}\right)$ : } \\
\hline Pentanenitrile & 191.98443 & 191.77800 & - & 0.20643 & 184.74555 \\
\hline 2-Propyn-1-amine, $N, N$-dimethyl- & 224.98199 & 224.73700 & - & 0.24499 & 217.52411 \\
\hline Propane, 2-isocyano-2-methyl- & 207.25172 & 208.10200 & - & -0.85028 & 199.71415 \\
\hline 2,5-Dihydro-1-methylpyrrole & 228.00784 & - & - & - & 220.36359 \\
\hline \multicolumn{6}{|l|}{ Alkyl amine (5) $\left(\mathrm{C}_{5} \mathrm{H}_{13} \mathrm{~N}\right)$ : } \\
\hline 1-Pentanamine & 220.37795 & 220.72200 & - & -0.34405 & 212.94769 \\
\hline$N$-ethyl- $N$-methylethanamine & 231.14915 & 232.07500 & - & -0.92585 & 223.59903 \\
\hline 2-Propanamine, $N, N$-dimethyl & 231.22570 & 231.97900 & - & -0.75330 & 223.66931 \\
\hline Tropylium & 251.90526 & 232.07500 & - & 19.83026 & 244.35263 \\
\hline \multicolumn{6}{|l|}{ Alkyl pyridine(1) $\left(\mathrm{C}_{6} \mathrm{H}_{7} \mathrm{~N}\right)$ : } \\
\hline 2-Methylpyridine & 225.59695 & 226.84000 & - & -1.24305 & 217.90376 \\
\hline 4-Methylpyridine & 225.69107 & 226.38600 & - & -0.69493 & 217.85230 \\
\hline Aniline & 210.44511 & 210.92300 & - & -0.47789 & 203.86575 \\
\hline 3-Methylpyridine & 224.81695 & - & - & - & 216.98885 \\
\hline 1-Cyclopentene-1-carbonitrile & 195.66289 & - & - & - & 188.66999 \\
\hline 2-Cyclopentene-1-carbonitrile & 194.02948 & - & - & - & 186.85398 \\
\hline 3-Methylenecyclobutanenitrile & 192.55672 & - & - & - & 185.42514 \\
\hline Bicyclo[2.1.0]pentane-1-carbonitrile & 197.48580 & - & - & - & 190.66798 \\
\hline$N$-2-propynyl-2-propyn-1-amine & 219.39528 & - & - & - & 211.61110 \\
\hline 5-Hexynenitrile & 189.48255 & - & - & - & 182.22987 \\
\hline 7-Azanorbornadiene & 228.60648 & - & - & - & 220.92709 \\
\hline 2,4-Hexadienenitrile & 197.80081 & - & - & - & 190.65857 \\
\hline \multicolumn{6}{|l|}{ Alkyl amine $(6)\left(\mathrm{C}_{6} \mathrm{H}_{15} \mathrm{~N}\right)$ : } \\
\hline Triethylamine & 233.79221 & 234.65600 & - & -0.86389 & 226.18185 \\
\hline 1-Hexanamine & 220.58880 & 221.67800 & - & -1.08920 & 213.16920 \\
\hline$N, N, 2$-trimethyl-2-propanamine & 233.23185 & 234.13000 & - & -0.89815 & 225.84363 \\
\hline
\end{tabular}


Table 2. Continued.

\begin{tabular}{|c|c|c|c|c|c|}
\hline & \multicolumn{3}{|c|}{$\begin{array}{l}\text { Proton affinity } \\
\qquad\left(\mathrm{kcal} \mathrm{mol}^{-1}\right)\end{array}$} & \multirow[t]{2}{*}{$\begin{array}{l}\Delta \mathrm{PA}^{\mathrm{a}} \\
\left(\mathrm{kcal} \mathrm{mol}^{-1}\right)\end{array}$} & \multirow[t]{2}{*}{$\begin{array}{l}\text { Gas-phase basicity } \\
\left(\mathrm{kcal} \mathrm{mol}^{-1}\right)\end{array}$} \\
\hline & CBS-QB3 & NIST & Other & & \\
\hline \multicolumn{6}{|l|}{ Alkyl pyridine $(2)\left(\mathrm{C}_{7} \mathrm{H}_{9} \mathrm{~N}\right)$ : } \\
\hline 2,6-Dimethylpyridine & 229.29298 & 230.16300 & - & -0.87002 & 221.83322 \\
\hline 2,4-Dimethylpyridine & 229.40530 & 230.13900 & - & -0.73370 & 222.49210 \\
\hline o-Toluidine & 211.85827 & 212.93000 & - & -1.07173 & 205.14085 \\
\hline N-Methylaniline & 218.22121 & 219.07300 & - & -0.85179 & 210.84679 \\
\hline p-Aminotoluene & 212.84157 & 214.31600 & - & -1.47443 & 206.28919 \\
\hline Benzenamine, 3-methyl & 212.48326 & 214.10100 & - & -1.61774 & 205.80287 \\
\hline 3,5-Dimethylpyridine & 227.80766 & 228.34600 & - & -0.53834 & 220.08058 \\
\hline 2,5-Dimethylpyridine & 228.59268 & 229.15900 & - & -0.56632 & 220.73445 \\
\hline 2,3-Dimethylpyridine & 228.58766 & 229.18300 & - & -0.59534 & 221.14421 \\
\hline 2-Ethylpyridine & 227.06218 & 227.62900 & - & -0.56682 & 219.24788 \\
\hline 3,4-Dimethylpyridine & 228.55879 & 228.80000 & - & -0.24121 & 221.00239 \\
\hline 3-Ethylpyridine & 226.49680 & 226.43400 & - & 0.06280 & 219.02762 \\
\hline Benzylamine & 220.85172 & 218.28400 & - & 2.56772 & 213.15728 \\
\hline 4-Ethylpyridine & 227.22094 & 227.31800 & - & -0.09706 & 219.54532 \\
\hline cyclo hexenecarbonitrile & 197.59185 & - & - & - & 190.64225 \\
\hline Bicyclo[3.1.0]hexane-1-carbonitrile & 198.44275 & - & - & - & 191.48688 \\
\hline N-Methyl-di(2-propynyl)-amine & 228.18856 & - & - & - & 220.11259 \\
\hline 2-Cyclohexene-1-carbonitrile & 192.92199 & - & - & - & 187.24931 \\
\hline 2-Pentynonitrile, 4,4-dimethyl & 192.36093 & - & - & - & 185.49731 \\
\hline 4-Cyanocyclohexene & 193.53312 & - & - & - & 186.36013 \\
\hline 1-Cyclopentylacetonitrile & 192.29818 & - & - & - & 185.31408 \\
\hline 1-Allylpyrrole & 227.52779 & - & - & - & 220.06113 \\
\hline \multicolumn{6}{|l|}{ Alkyl pyridine(3) $\left(\mathrm{C}_{8} \mathrm{H}_{11} \mathrm{~N}\right)$ : } \\
\hline 2,6-Xylidine & 213.09885 & 215.51100 & - & -2.41215 & 206.96251 \\
\hline 2-(i-C3H7)-pyridine & 227.43116 & 228.58500 & - & -1.15384 & 220.06364 \\
\hline 2-Propylpyridine & 227.33828 & 228.41800 & - & -1.07972 & 219.71412 \\
\hline 4-Isopropylpyridine & 227.20149 & 228.41800 & - & -1.21651 & 219.81327 \\
\hline 3-Ethylaniline & 212.48326 & 214.60300 & - & -2.11974 & 206.11286 \\
\hline Quinoline & 226.87142 & 227.82000 & - & -0.94858 & 219.28428 \\
\hline \multicolumn{6}{|l|}{ Alkyl amine (8) $\left(\mathrm{C}_{8} \mathrm{H}_{19} \mathrm{~N}\right)$ : } \\
\hline Diisopropylethylamine & 236.82183 & 237.64300 & - & -0.82117 & 228.45846 \\
\hline 1-Octanamine & 220.80968 & 222.01200 & - & -1.20232 & 213.38444 \\
\hline Di-tert-butylamine & 234.67073 & 236.11400 & - & -1.44327 & 227.08296 \\
\hline \multicolumn{6}{|l|}{ Alkyl pyridine(4) $\left(\mathrm{C}_{9} \mathrm{H}_{13} \mathrm{~N}\right)$ : } \\
\hline 2,6-Diethylpyridine & 231.83941 & 232.38500 & - & -0.54559 & 224.68776 \\
\hline Benzenamine, N-ethyl-N-methyl & 227.14752 & 225.16700 & - & 1.98052 & 219.32946 \\
\hline Benzenamine, N,N,3-trimethyl & 226.78106 & 224.42600 & - & 2.35506 & 219.18701 \\
\hline \multicolumn{6}{|l|}{ Alkyl quinoline(1) $\left(\mathrm{C}_{10} \mathrm{H}_{9} \mathrm{~N}\right)$ : } \\
\hline 8-Methylquinoline & 228.51926 & $\begin{array}{l}210.1 / 800 \\
-\end{array}$ & $\begin{array}{l}- \\
-\end{array}$ & 0.81381 & $\begin{array}{l}210.51980 \\
220.78716\end{array}$ \\
\hline \multicolumn{6}{|l|}{ Alkyl pyridine $(5)\left(\mathrm{C}_{10} \mathrm{H}_{15} \mathrm{~N}\right)$ : } \\
\hline $\mathrm{N}, \mathrm{N}$-diethylaniline & 228.42325 & 229.39800 & - & -0.97475 & 220.67923 \\
\hline Benzenamine, N,N,2,6-tetramethyl & 228.46592 & 228.03500 & - & 0.43092 & 220.37426 \\
\hline Benzenamine, N,N,3,5-tetramethyl & 228.30214 & 228.51300 & - & -0.21086 & 220.83297 \\
\hline 2-Methyl-4,6-diethylpyridine & 234.42537 & - & - & - & 227.51155 \\
\hline \multicolumn{6}{|l|}{ Alkyl quinoline(2) $\left(\mathrm{C}_{11} \mathrm{H}_{11} \mathrm{~N}\right)$ : } \\
\hline
\end{tabular}

${ }^{\text {a }}$ Proton affinity difference calculated as $\triangle \mathrm{PA}=\left(\mathrm{PA}_{\mathrm{CBS}-\mathrm{QB} 3}-\mathrm{PA}_{\mathrm{NIST}}\right){ }^{\mathrm{b}}{ }^{\mathrm{W}} \mathrm{W} 1$ at $298 \mathrm{~K}$, Parthiban and Martin, $2001 ;{ }^{\mathrm{c}} \mathrm{G} 2$ at $298 \mathrm{~K}$, Smith and Radom, 1993; ${ }^{\mathrm{d}}$ modified G2MS at $298 \mathrm{~K}$, Elrod, 2003; ${ }^{\mathrm{d}}$ G2(MP2, SVP) at $298 \mathrm{~K}$, Smith and Radom, 1995. 
where $\mathrm{GB}(\mathrm{A})-\mathrm{GB}(\mathrm{B})$ and $\mathrm{PA}(\mathrm{A})-\mathrm{PA}(\mathrm{B})$ are the differences in gas-phase basicities and proton affinities (respectively) of $\mathrm{A}$ and $\mathrm{B}$. The latter expression assumes that the difference in gas-phase basicities is roughly the same as the difference in proton affinities. As stated before, proton affinities are related to Gibbs free energy, and gas-phase basicities are related to enthalpy. Thus, looking at Eq. (1) we can see that, for the latter equation to hold (for a constant temperature), the difference in the changes of entropy between the proton transfer reactions leading to $\mathrm{HA}^{+}$and $\mathrm{HB}^{+}$must be small - at least compared to the changes in proton affinity and gas-phase basicity. This is usually valid because the number of gas-phase molecules does not change in a proton transfer reaction of the type $\mathrm{HA}^{+}+\mathrm{B}<=>\mathrm{A}+\mathrm{HB}^{+}$, implying a rather small entropy change and thus also a rather small difference in the change of entropy between two such reactions. Even in cases where the equilibrium expression does not strictly apply (e.g., due to too low concentrations of $A$ or $B$ ), the quantities $\mathrm{GB}(\mathrm{A})-\mathrm{GB}(\mathrm{B})$ or $\mathrm{PA}(\mathrm{A})-\mathrm{PA}(\mathrm{B})$ can still be used as a qualitative indicator: if the proton affinity of $\mathrm{A}$ is much lower than that of $\mathrm{B}$, then $[\mathrm{A}] /[\mathrm{B}]$ will be much lower than $\left[\mathrm{HA}^{+}\right] /\left[\mathrm{HB}^{+}\right]$. In the cases under study, the difference between the proton affinities and gas-phase basicities of a molecule varied between $\sim 5.7 \mathrm{kcal} \mathrm{mol}^{-1}$ (2-Cyclohexene-1-carbonitrile) and $\sim 8.4 \mathrm{kcal} \mathrm{mol}^{-1}$ (Diisopropylethylamine). If we compare these two cases, the difference between $\mathrm{GB}(\mathrm{A})-\mathrm{GB}(\mathrm{B})$ and $\mathrm{PA}(\mathrm{A})-\mathrm{PA}(\mathrm{B})$ is $\sim 2.7 \mathrm{kcal} \mathrm{mol}^{-1}$ while the actual differences in gas-phase basicities and proton affinities is slightly over $40 \mathrm{kcal} \mathrm{mol}^{-1}$. This means an error of less than $7 \%$. For the majority of molecule pairs that can be formed from the cases under study here, the difference is less than $1 \mathrm{kcal} \mathrm{mol}^{-1}$. If the two molecules have gas-phase basicities or proton affinities that are close to each other, even a $1 \mathrm{kcal} \mathrm{mol}^{-1}$ difference in the TS term may lead to a large relative error. In such cases, however, it should be clear that the ratio $\left[\mathrm{HA}^{+}\right] /\left[\mathrm{HB}^{+}\right]$depends predominately on the ratio $[\mathrm{A}] /[\mathrm{B}]$ and not the gas-phase basicities or proton affinities.

Applying this reasoning to ambient ion measurements is complicated by the fact that a single molecular formula may correspond to several different structural isomers, with different proton affinities. The acyclic alkylamines with only a few carbon atoms have only a few isomers, and $\mathrm{C}_{5} \mathrm{H}_{5} \mathrm{~N}$ very likely corresponds solely to pyridine (according to our calculations, it also has the largest proton affinity of the isomers listed in NIST), but most other carbon-nitrogen-hydrogen compounds have multiple structural isomers. Thus, some information on the emission sources of neutral nitrogencontaining bases, or alternative chemical information such as gas chromatography data, is needed before extensive comparisons can be made.

Bearing this in mind, we can nevertheless use our computed proton affinities together with the three cation peaks with the highest concentrations in the measurements of Ehn et al. (2010) to conclude tentatively that pyridine likely has a higher concentration than any of the alkyl di- or triamines, since the concentration of protonated pyridine is so much higher despite a lower (or in some cases similar) proton affinity. Based on similar reasoning, if we assume that the peaks labeled as alkyl pyridine (1) and alkyl pyridine (2) indeed correspond to substituted pyridines rather than, for example, anilines or nitriles, we can conclude that these compounds have much higher concentrations than either the acyclic amines or the more highly substituted pyridines. If these peaks instead correspond to protonated anilines or nitriles, then their neutral concentrations would need to be larger still, as these compounds have much lower proton affinities than the substituted pyridines. Similarly, methylpyridines likely have a higher concentration than either pyridine or 2alkylpyridines. Many more similar arguments could be made using the peaks with lower concentrations (e.g., alkyl quinolines likely have lower concentrations than quinoline), but as the lower concentration values are likely more affected by random errors, conclusions drawn from them are likely less reliable.

\section{Conclusions}

The CBS-QB3 model chemistry method proved to be a quick and accurate way to obtain theoretical values for proton affinities. Several new proton affinities were determined, and overall agreement with previous results was good. Comparing the obtained proton affinities and previous ambient ion measurements gave some indications of the relative atmospheric concentrations of the precursor neutral molecules.

\section{Supplementary material related to this article is available online at http://www.atmos-chem-phys.net/13/ 10397/2013/acp-13-10397-2013-supplement.zip.}

Acknowledgements. We thank the CSC - IT Center for Science Ltd. for computer time and technical assistance. We also thank Mikael Ehn for his assistance. The financial support by the Academy of Finland (Centre of Excellence program project No. 1118615 and LASTU program project No. 135054), ERC StG 257360-MOCAPAF and National Science Foundation Graduate Research Fellowship to J. Faust under grant No. DGE-0718123 is gratefully acknowledged.

Edited by: I. Riipinen

\section{References}

ADF-GUI 2012.01, SCM, Amsterdam, The Netherlands, http:// www.scm.com, 2012.

Ahlrichs, R., Baer, M., Haeser, M., Horn, H., and Koelmel, C.: Electronic structure calculations on workstation computers: The program system turbomole, Chem. Phys. Lett. ,162, 165-169, 1989. 
Barnes, E. C., Petersson, G. A., Montgomery Jr., J. A., Frisch, M. J., and Martin, J. M. L.: Unrestricted Coupled Cluster and Brueckner Doubles Variations of W1 Theory, J. Chem. Theory Comput., 5, 2687-2693, 2009.

Becke, A. D.: Density-functional thermochemistry. III. The role of exact exchange, J. Chem. Phys., 98, 5648-52, 1993.

Curtiss, L. A., Raghavachari, K., Trucks, G. W., and Pople, J. A.: Gaussian-2 theory for molecular energies of first- and secondrow compounds, J. Chem. Phys., 94, 7221-7230, 1991.

Curtiss, L. A., Raghavachari, K., and Pople, J. A.: Gaussian-2 theory using reduced Møller-Plesset orders, J. Chem. Phys., 98, 1293-1298, 1993.

Curtiss, L. A., Raghavachari, K., Redfern, P. C., Rassolov, V., and Pople, J. A.: Gaussian-3 (G3) theory for molecules containing first and second-row atoms, J. Chem. Phys., 109, 7764-7776, 1998.

Curtiss, L. A., Redfern, P. C., and Raghavachari, K.: Gaussian-4 theory, J. Chem. Phys., 126, 084108, doi:10.1063/1.2436888, 2007.

Czakó, G., Mátyus, E., Simmonett, A. C., Császár, A. G., Schaefer III, H. F., and Allen, W. D.: Anchoring the Absolute Proton Affinity Scale, J. Chem. Theory Comput., 4, 1220-1229, 2008.

Eisele, F. and Tanner, D.: Ion-assisted tropospheric $\mathrm{OH}$ measurements, J. Geophys. Res., 96, 9295-9308, 1991.

Ehn, M., Junninen, H., Petäjä, T., Kurtén, T., Kerminen, V.-M., Schobesberger, S., Manninen, H. E., Ortega, I. K., Vehkamäki, H., Kulmala, M., and Worsnop, D. R.: Composition and temporal behavior of ambient ions in the boreal forest, Atmos. Chem. Phys., 10, 8513-8530, 2010,

http://www.atmos-chem-phys.net/10/8513/2010/.

Elrod, M. J.: A comprehensive computational investigation of the enthalpies of formation and proton affinities of $\mathrm{C} 4 \mathrm{H} 7 \mathrm{~N}$ and C3H3ON compounds, Int. J. Mass Spectrom., 228, 91-105, 2003.

Frisch, M. J., Trucks, G. W., Schlegel, H. B., Scuseria, G. E., Robb, M. A., Cheeseman, J. R., Scalmani, G., Barone, V., Mennucci, B., Petersson, G. A., Nakatsuji, H., Caricato, M., Li, X., Hratchian, H. P., Izmaylov, A. F., Bloino, J., Zheng, G., Sonnenberg, J. L., Hada, M., Ehara, M., Toyota, K., Fukuda, R., Hasegawa, J., Ishida, M., Nakajima, T., Honda, Y., Kitao, O., Nakai, H., Vreven, T., Montgomery Jr., J. A., Peralta, J. E., Ogliaro, F., Bearpark, M., Heyd, J. J., Brothers, E., Kudin, K. N., Staroverov, V. N., Kobayashi, R., Normand, J., Raghavachari, K., Rendell, A., Burant, J. C., Iyengar, S. S., Tomasi, J., Cossi, M., Rega, N., Millam, J. M., Klene, M., Knox, J. E., Cross, J. B., Bakken, V., Adamo, C., Jaramillo, J., Gomperts, R., Stratmann, R. E., Yazyev, O., Austin, A. J., Cammi, R., Pomelli, C., Ochterski, J. W., Martin, R. L., Morokuma, K., Zakrzewski, V. G., Voth, G. A., Salvador, P., Dannenberg, J. J., Dapprich, S., Daniels, A. D., Farkas, O., Foresman, J. B., Ortiz, J. V., Cioslowski, J., and Fox, D. J.: Gaussian 09, Revision A.01, Gaussian, Inc., Wallingford CT, 2009.

Head-Gordon, M., Pople, J. A., and Frisch, M. J.: MP2 energy evaluation by direct methods, Chem. Phys. Lett., 153, 503-506, 1988.
Hunter, E. P. L. and Lias, S. G.: Evaluated Gas Phase Basicities and Proton Affinities of Molecules: An Update, J. Phys. Chem. Ref. Data, 27, 413-656, 1998.

Kupiainen, O., Ortega, I. K., Kurtén, T., and Vehkamäki, H.: Amine substitution into sulfuric acid - ammonia clusters, Atmos. Chem. Phys., 12, 3591-3599, 2012,

http://www.atmos-chem-phys.net/12/3591/2012/.

Lee, C., Yang, W., and Parr, R. G.: Development of the ColleSalvetti correlation-energy formula into a functional of the electron density, Phys. Rev. B, 37, 785-789, 1988.

Martin, J. M. L. and de Oliveira, G.: Towards standard methods for benchmark quality ab initio thermochemistry-W1 and W2 theory, J. Chem. Phys., 111, 1843-1856, 1999.

McLafferty, F. W.: Mass Spectrometric Analysis, Molecular Rearrangements, Anal. Chem., 31, 82-87, 1959.

Møller, C. and Plesset, M. S.: Note on an Approximation Treatment for Many-Electron Systems, Phys. Rev. 46, 618 pp., 1934.

Montgomery Jr., J. A., Frisch, M. J., Ochterski, J. W., and Petersson, G. A.: A complete basis set model chemistry, VI. Use of density functional geometries and frequencies, J. Chem. Phys., 110, 2822-2827, 1999.

Montgomery Jr., J. A., Frisch, M. J, Ochterski, J. W., and Petersson, G. A.: A complete basis set model chemistry, VII. Use of the minimum population localization method, J. Chem. Phys., 112, 6532-6542, 2000.

Ochterski, J. W., Petersson, G. A., and Montgomery Jr., J. A.: A complete basis set model chemistry, V. Extensions to six or more heavy atoms, J. Chem. Phys., 104, 2598-2619, 1996.

Parthiban, S. and Martin, J. M. L.: Assessment of W1 and W2 theories for the computation of electron affinities, ionization potentials, heats of formation, and proton affinities, J. Chem. Phys., 114, 6014-6029, doi:10.1063/1.1356014, 2001.

Raghavachari, K., Trucks, G. W., Pople J. A., and Head-Gordon, M. A.: A fifth-order perturbation comparison of electron correlation theories, Chem. Phys. Lett., 157, 479-483, 1989.

Rappe, A. K., Casewit, C. J., Colwell, K. S., Goddard III, W. A., and Skiff, W. M.: UFF, a Full Periodic Table Force Field for Molecular Mechanics and Molecular Dynamics Simulations, J. Am. Chem. Soc., 114, 10024-10035, 1992.

Ryding, M. J., Ruusuvuori, K., Andersson, P. U., Zatula, A. S., McGrath, M. J., Kurtén, T., Ortega, I. K., Vehkamäki, H., and Uggerud, E.: Structural Rearrangements and Magic Numbers in Reactions between Pyridine-Containing Water Clusters and Ammonia, J. Phys. Chem. A., 116, 4902-4908, 2012.

Smith, B. J. and Radom, L.: Assigning absolute values to proton affinities: a differentiation between competing scales, J. Am. Chem. Soc., 115, 4885-4888, doi:10.1021/ja00064a058, 1993.

Smith, B. J. and Radom, L.: Calculation of Proton Affinities Using the G2(MP2,SVP) Procedure, J. Phys. Chem., 99, 6468-6471, 1995.

Trucks, G. W., Watts, J. D., Salter, E. A., and Bartlett, R. J.: Analytical MBPT(4) gradients, Chem. Phys. Lett., 153, 490-495, 1988. 